\title{
Relationships among Secondary School Teacher Multicultural Education Beliefs, Perceived Multicultural Education Praxis, Gender and Workshop Attendance
}

\author{
Su-ching Lin, Ph. D. \\ Professor, Department of Education, National Changhua University of Education \\ 1, Jin De Road, Paisha Village, Changhua 500, Taiwan \\ Tel: 886-4723-2105\# $5701 \quad$ E-mail: sclin@cc.ncue.edu.tw \\ Jing-Tong $\mathrm{Wu}$ \\ $\mathrm{Ph}$. D. candidate, Department of Education \\ National Changhua University of Education, Taiwan
}

Received: June 30, 2014 Accepted: July 16, 2014 Published: August 1, 2014

doi:10.5296/jse.v4i3.5890

URL: http://dx.doi.org/10.5296/jse.v4i3.5890

\begin{abstract}
This study examined the relationships among secondary school teacher perceptions of multicultural education belief (MCEB), multicultural education praxis (MCEP), teachers' gender, ethnicity, and attendance of multicultural education (MCE) workshop. The participants were 464 secondary school teachers from central Taiwan. Descriptive statistics, $t$-test, product moment correlation, and multiple regressions were applied to analyze the data. The analytical results showed that significant differences were found between teachers' gender and attendance of MCE workshop. A positive and significant correlation between perceived MCEB and MCEP, i.e., perceived MCEB could predict perceived MCEP. At levels of teaching strategy, learning assessment, classroom management, and overall, the MCEB dimension, special need was the strongest predictor of perceived MCEP. At curriculum design level, ethnicity and special need were the best predictors of perceived MCEP. Teachers' attendance of MCE workshop could significantly predict perceived MCEP at levels of teaching strategy, curriculum design, learning assessment, classroom management, and overall. However, perceived MCEB could not be predicted from teacher's gender.
\end{abstract}

Keywords: multicultural education belief, multicultural education praxis, secondary school teachers 


\section{Introduction}

The 21st Century has been characterized by globalization, an ongoing process of intensified economic, social, and cultural exchanges. Globalization is challenging to schools in multiple ways (Suárez-Orozco \&Sattin, 2007). Students in classrooms today have diverse racial, ethnic, linguistic, socio-economic, gendered, religious, and cultural backgrounds. As globalization continues, student diversity will continue to increase worldwide, such that teachers and schools face many challenges in providing each student with the same opportunities to achieve at his or her potential (Ambe, 2006; UNESCO, 2004). Moreover, regardless of gender, ethnicity, social class, cultural roots, or special needs, students must develop accepting racial and ethnic attitudes, such that they can function effectively in culturally diverse democratic societies (Banks, 2004).

Multicultural education (MCE), an educational reform movement emerged in the 1960s and $70 \mathrm{~s}$ in response to ethnic revitalization movements and immigration in Western nations. The primary aim of MCE is structure schools, colleges, and universities so students from diverse racial, ethnic, cultural, linguistic, and religious groups, as well as social classes, will have equal educational opportunities, and develop democratic attitudes that make them rethink and revise their identities (Banks, 2004; Fullinwider, 2001). In the 1970s and 80s, MCE, especially within the USA, has been given to issues related to gender and social class (Banks, 2004).

Perkins (2012) noted the two major goals of multiculturalism are to enable service providers to recognize, accept, and appreciate differences in culture, ethnicity, social class, sexual orientation, religion, special needs, and gender, and to instill in people a sense of social justice and equality. Williams, Nichols, and Williams (2013) indicated that multicultural awareness and knowledge should not be limited by race, ethnicity, gender, sexual orientation, religious affiliation, mental/physical abilities, and socio-economic status, but is defined as understanding, sensitivity, and appreciation of the history, values, experiences, and lifestyles of groups and individuals.

The main challenge of MCE is the all educational actors work together (Hachfeld, Hahn, Schroeder, Anders, Stanat, Kunter, 2011). Specifically, the multicultural competence of teachers has been considered a key factor when assessing whether schooling successfully teach multicultural perspectives to students. Given their central role in education, teachers have a key function in that, for example, the classroom environment created by teachers can be space where diversity thrives, potentially improving all dimensions of campus life. Peterson and Spencer (1990) showed that a classroom with diversity positively impacts student outcomes, particularly when pedagogy, curriculum design, teaching strategies, learning assessments, and classroom management are considered along with the compositional diversity of students. Many researchers (Ambe, 2006; Banks, 1997; Bennett, 2003; Davidman \& Davidman, 2001; Henson, 2004; Manning \& Baruth, 2004) have written on how to best modify a curriculum and its teaching materials such that they reflect multiple cultural perspectives, representing the richness of the entire human experience. The academic performances of minority students increase when teachers understand and consider the 
students' cultural and ethnic backgrounds, and including family and community sources when developing curricula (Stevenson \& Gonzalez, 1992). That is, teachers can maximize the educational benefits of diversity in the classroom via curriculum design and teaching strategies that address diversity and MCE issues (Ndura \& Dogbevia, 2013).

A large body of evidence from various countries shows that the beliefs of teachers significantly influence how they plan, organize, and implement their lessons and how responsive they are to their students (Fong \& Sheets, 2004; Leonard \& Leonard, 2006; McCall, 1995; Montano, Lopez-Torres, \& DeLissovoy, 2002; Staub \& Stern, 2002; Stipek, Givvin, Salmon, \& MacGyvers, 2001), however, little is known about the attitudes, views, and beliefs about cultural diversity of teachers (Vedder, Horenczyk, Liebkind, \& Nickmans, 2006). Moreover, measures to improve educational outcomes for learners with diverse backgrounds should be directly linked to teaching practices and the ways in which teachers are trained. The distance between student diversity and homogeneous teaching forces has induced an urgent call for multicultural teacher education to prepare teachers in cultural competence and to work effectively with a diverse student body (National Council for Accreditation of Teacher Education, 2008). Sogunro (2001) has stated that although most teachers are competent in their subject areas, they lack the knowledge, skills and attitudes necessary to successfully teach and manage diverse student populations. Teachers must acquire multicultural competencies that become a deep appreciation for diversity and guide culturally relevant teaching (Ambe, 2006). Evidence also shows that courses or workshops in MCE positively impact on the views of in-service teachers (Edwards \& Kuhlman, 2007; Wiggins, Follo, \& Eberly, 2007).

As part of a loosely interconnected global system, Taiwan cannot escape influences of globalization on educational innovation. Among the many relevant legislative tools, the revised University Law, Teacher Education Act, and Law of Teacher Union and Teacher Selection are considered particularly significant in restructuring Taiwan's education system (Yang, 2002). The Administrative Guideline for Accreditation of Teacher Education Programs (Ministry of Education, 2002) encourages universities to develop teacher training programs that address diversity in the student population. In response, many universities new offer MCE in their teacher education programs. In-service teachers are also encouraged to attend MCE workshops or programs to cultivate their knowledge, skills and attitudes that are deemed necessary to successfully teach and manage classroom diversity. However, do these workshops positively impact on the views of in-service teachers? This study examines the difference between MCEB and MCEP of secondary school teachers who attend MCE workshops and their secondary school counterparts who never attend an MCE workshop? Moreover, perceived MCEBs and MCEP may be altered by teacher's gender. Thus, determining whether gender affect perceived MCEBs and MCEP in the Taiwanese context is essential. As mentioned, little is known about the attitudes, views, and beliefs about cultural diversity of teachers (Vedder et al., 2006). Therefore, this study examines the relationships among teachers' MCEBs, MCEP, gender and attendance record for MCE workshops. Findings will provide valuable data and enhance the understanding of MCEBs and MCEP in different cultural contexts. 


\section{Methodology}

\subsection{Participants}

Four hundred eighty secondary teachers from central Taiwan were invited to complete teacher MCEB and MCEP questionnaires. To ensure confidentiality, each questionnaire was completed anonymously. With a response rate of $96.7 \%, 464$ teachers returned completed questionnaires, including $61.4 \%$ female $(n=285)$ and $38.6 \%$ male $(n=179)$. Of whom, $41.4 \%$ $(n=192)$ had been attended MCE workshop and 58.6\% $(n=272)$ had not been attended any MCE workshop.

\subsection{Instruments}

\subsubsection{Perceived MCEB}

The Multicultural Education Belief Scale (MCEBS) developed by the authors based on previous studies (Hou, 2010; Tang, 2009; Wen, 2008) was administered to measure what teachers believe about cultural diversity in the classroom using 26 items in five dimensions, namely, pedagogy, gender, ethnicity, social class, and special needs. The first dimension, pedagogy (5 items) identified teachers' attitudes, views, and opinions related to teaching culturally diverse students. The second dimension, gender (4 items) measured the teachers' attitudes, views and opinions related to gender equality. The third dimension, ethnicity (4 items) measured teachers' attitudes, views, and opinions related to equality among ethnicities. The fourth dimension, social class (6 items) assessed teachers' attitudes, views, and opinions related for different social-economic classes. The fifth dimension, special needs ( 7 items) identified teachers' attitudes, views, and opinions related to students with special needs, including mental and physical needs. Teachers responded to the items on a five-point Likert scale, ranging from 1 for "strongly disagree" to 5 for "strongly agree".

The factor analysis made on data obtained by MCEBS in the current application reveals that the value of composite reliability (CR) is .86 and the value of average variance extracted is .56, indicating good validity of the items within this scale. The overall internal consistency (Cronbach's $\alpha=.93$ ) for the scale in the current sample was good. The Cronbach's $\alpha$ for the five subscales ranged from .76 to .90 , indicating good internal consistencies of the items within each subscale.

\subsubsection{Perceived MCEP}

Another research instrument, the Perceived Multicultural Education Praxis Scale (MCEPS), was developed by the authors based on previous studies (Hou, 2010; Tang, 2009; Wen, 2008). This 28-items scale measures how teachers respond to and deal with cultural diversity via four dimensions: teaching strategy, curriculum design, learning assessment, and classroom management. The first dimension, teaching strategy (7 items), was assessed teachers' perceptions of teaching strategies for students of different genders, ethnicities, social classes, and abilities. The second dimension, curriculum design (7 items) identified teachers' perceptions of curriculum design for students of different genders, ethnicities, social classes, and abilities. The third dimension, learning assessment ( 7 items) identified teachers' 
assessment methods for students of different genders, ethnicities, social classes, and abilities. The fourth dimension, classroom management ( 7 items) measured teachers' classroom management strategies for students of different genders, ethnicities, social classes, and abilities. Teachers responded to the items on a five-point Likert scale, ranging from 1 for "strongly disagree" to 5 for "strongly agree".

The factor analysis made on data obtained by MCEPS in the current application reveals that the value of composite reliability (CR) is .85 and the value of average variance extracted is .59 , indicating good validity of the items within this scale. The overall internal consistency (Cronbach's $\alpha=.88$ ) for the scale in the current sample was good. The Cronbach's $\alpha$ for the four subscales ranged from .76 to .89 , indicating good internal consistencies of the items within each subscale.

\subsection{Data analysis}

The statistical program SPSS 20.0 for windows was used for data analysis. First of all, five composite scores of pedagogy, gender, ethnics, social class, and special need were computed for each respondent by adding the scores on the 26, 5, 4, 4, 6, and 7 items in the perceived MCEB respectively measuring overall, pedagogy, gender, ethnicity, social class, and special need. Similarly, a total perceived MCEP score as well as four additional composite MCEP scores were computed by adding the scores on the 28, 7, 7, 7 and 7 items, respectively, measuring total MCEP, teaching strategy, curriculum design, learning assessment, and classroom management. Descriptive statistics and product moment correlation coefficients were then computed for all variables in order to examine relationships among teacher gender, attendance of MCE workshop, perceived MCEB and MCEP. In addition, a series of $t$-tests was used to compare teacher gender (male, female) and attendance of workshop (yes, no) as independent variables on the categories of perceived MCEB and MCEP as dependent variables. Finally, regression analysis was used to test with overall MCEP, teaching strategy, curriculum design, learning assessment, and classroom management as dependent variables and dimension of pedagogy, gender, ethnicity, social class, and special need teachers' gender and attendance of workshop as independent variables to determine if the teacher perceived MCEB, teachers' gender, and attendance of workshop predicted perceived MCEP.

\section{Results}

All statistical tests used to address the questions in this study used .05 as the minimum alpha level. The following tables present some descriptive statistics about variables as well as highlights from the inter-correlations matrix of the variables and the results of the independent sample $t$-test and multiple regression analysis run in this study.

\section{1 difference analyses in gender and attendance of $M C E$ workshop on teacher MCEB}

Table 1 showed difference analysis results, which indicated that a significant difference between male teachers and female teachers in pedagogy dimension $(t=-2.02, p<.05)$. The significant result indicating female teachers had a higher score on pedagogy dimension than male teachers. However, no significant differences were found between male teachers and 


\section{Macrothink}

female teachers in another four dimensions, including gender, ethnicity, social class, and special need.

Table 1 also indicated a significant difference between teachers who had been attended MCE workshop and teachers who never attended MCE workshop in dimensions of gender $(t=2.13$, $p<.05)$ and social class $(t=2.84, p<.01)$. The significant results indicating teachers who had been attended MCE workshop had a higher score on gender and social class dimensions than teachers who never attended MCE workshop. In contrast, no significant differences were found between teachers who had been attended MCE workshop and teachers who never attended MCE workshop in another three dimensions, including pedagogy, ethnicity, and special need.

Table 1. $t$-tests of gender and attendance of MCE workshop on dimensions of perceived MCEB

\begin{tabular}{lccccccccccc}
\hline MCEB/ & \multicolumn{3}{l}{$\operatorname{male}(n=179)$} & \multicolumn{2}{c}{ female $(n=285)$} & \multicolumn{3}{c}{$\operatorname{yes}(n=192)$} & \multicolumn{2}{c}{ no $(n=272)$} \\
Dimension & $\mathrm{M}$ & $\mathrm{SD}$ & $\mathrm{M}$ & $\mathrm{SD}$ & $t$ & $\mathrm{M}$ & $\mathrm{SD}$ & $\mathrm{M}$ & $\mathrm{SD}$ & $t$ \\
\hline pedagogy & 4.39 & .50 & 4.48 & .45 & $-2.02^{*}$ & 4.49 & .45 & 4.42 & .49 & 1.75 \\
gender & 4.37 & .52 & 4.45 & .90 & -1.26 & 4.51 & 1.04 & 4.35 & .51 & $2.13^{*}$ \\
ethnicity & 4.10 & .59 & 4.20 & .54 & -1.82 & 4.23 & .55 & 4.12 & .57 & 1.97 \\
social class & 4.21 & .51 & 4.21 & .48 & .06 & 4.28 & .49 & 4.16 & .48 & $2.84^{* *}$ \\
special need & 4.23 & .48 & 4.23 & .46 & 1.34 & 4.30 & .45 & 4.23 & .48 & 1.63 \\
\hline
\end{tabular}

$* p<.05 . * * p<.01$.

\section{2 difference analyses in gender and attendance of MCE workshop on perceived MCEP}

Table 2 showed difference analysis results, which indicated significant differences were found between teachers who had been attended MCE workshop and teachers who never attended MCE workshop in four MCEP dimensions, including teaching strategy $(t=3.83, p$ $<.001)$, curriculum design( $(t=5.25, p<.001)$, learning assessment $(t=4.33, p<.001)$, and classroom management $(t=4.89, p<.001)$. Significant results indicating the teachers who have been attended MCE workshop had a higher score on all of MCEB dimensions than teachers who never attended MCE workshop. In contrast, no significant differences were found between male teachers and female teachers in perceived MCEP. In contrast, 
Table 2. $t$-tests of gender and attendance of MCE workshop on dimensions of perceived MCEP

\begin{tabular}{|c|c|c|c|c|c|c|c|c|c|c|}
\hline MCEP/ & \multicolumn{2}{|c|}{ male $(n=179)$} & \multicolumn{2}{|c|}{ female $(n=285)$} & \multirow[b]{2}{*}{$t$} & \multicolumn{2}{|c|}{$\operatorname{yes}(n=192)$} & \multicolumn{2}{|c|}{$\underline{\text { no }(n=272)}$} & \multirow[b]{2}{*}{$t$} \\
\hline Dimension & M & SD & $\mathrm{M}$ & $\mathrm{SD}$ & & M & $\mathrm{SD}$ & M & SD & \\
\hline Teaching strategy & 4.23 & .62 & 4.14 & .47 & 1.67 & 4.29 & .59 & 4.10 & .47 & $3.83 * * *$ \\
\hline Curriculum design & 3.59 & .71 & 3.51 & .60 & 1.24 & 3.72 & .60 & 3.41 & .64 & $5.25 * * *$ \\
\hline Learning assessment & 3.89 & .56 & 3.88 & .56 & .28 & 4.02 & .56 & 3.79 & .54 & $4.33 * * *$ \\
\hline Classroom management & 3.65 & .61 & 3.57 & .58 & 1.41 & 3.76 & .59 & 3.49 & .57 & $4.89 * * *$ \\
\hline
\end{tabular}

$* * * p<.001$.

\subsection{Correlational analysis between perceived MCEB and MCEP}

Table 3 presents the inter-correlations among MCEB and MCEP. It can be seen that the five constructs of MCEB significantly correlated with each other, ranging from .38 to $.73(p<.01)$. Similarly, four constructs of MCEP significantly correlated each other, ranging from 22 to . $86(p<.01)$. As Table 3 showed, the five MCEB subscales and four MCEP subscales significantly correlated with each other. For correlated with perceived MCEP and MCEB, at teaching strategy level, the highest correlations were those related to special need $(r=.59, p$ $<.01)$, whereas the lowest correlations were those related to gender $(r=.34, p<.01)$. At curriculum design level, the highest correlations were those related to ethnicity $(r=.35, p<.01)$ and special need $(r=.35, p<.01)$, whereas the lowest correlations were those related to pedagogy $(r=.19, p<.01)$. At learning assessment, the highest correlations were those related to special need $(r=.52, p<.01)$, whereas the lowest correlations were those related to gender $(r=.33, p<.01)$. At classroom management, the highest correlations were those related to special need $(r=.43, p<.01)$, whereas the lowest correlations were those related to pedagogy $(r=.22, p<.01)$. At Overall level, the highest correlations were those related to special need $(r=.56, p<.01)$, whereas the lowest correlations were those related to gender $(r=.35, p$ $<.01)$.

In summary, positive and significant correlations were found among the five MCEB dimensions, and among the four dimensions. Dimensions of ethnicity and special need showed higher correlations than other dimensions in MCEB with perceived MCEP. 


\section{Macrothink}

Table 3. Pearson product-moment correlation between perceived MCEB and perceived $\operatorname{MCEP}(\mathrm{n}=464)$

\begin{tabular}{|c|c|c|c|c|c|c|c|c|c|c|c|}
\hline variables & $\mathrm{M}$ & SD & 1 & 2 & 3 & 4 & 5 & 6 & 7 & 8 & 9 \\
\hline MCEB(overall) & 4.30 & .44 & $.78^{* *}$ & $.73^{* *}$ & $.81^{* *}$ & $.84^{* *}$ & $.80^{* *}$ & $.59^{* *}$ & $.37^{* *}$ & $.56^{* *}$ & $.43^{* *}$ \\
\hline 1.padegogy & 4.45 & .47 & 1 & & & & & & & & \\
\hline 2. gender & 4.42 & .78 & $.45^{* *}$ & 1 & & & & & & & \\
\hline 3. ethnicity & 4.16 & .568 & $.57^{* *}$ & $.38^{* *}$ & 1 & & & & & & \\
\hline 4. social class & 4.21 & .49 & $.60^{* *}$ & $.41^{* *}$ & $.72^{* *}$ & 1 & & & & & \\
\hline 5.special need & 4.26 & .47 & $.57^{* *}$ & $.41^{* *}$ & $.60^{* *}$ & $.73^{* *}$ & 1 & & & & \\
\hline$M C E P$ (overall) & 3.80 & .48 & $.36^{* *}$ & $.35^{* *}$ & $.52^{* *}$ & $.53^{* *}$ & $.56^{* *}$ & $.75^{* *}$ & $.85^{* *}$ & $.86^{* *}$ & $.86^{* *}$ \\
\hline 6. teaching strategy & 4.17 & .53 & $.43^{* *}$ & $.34^{* *}$ & $.49^{* *}$ & $.54^{* *}$ & $.59^{* *}$ & 1 & & & \\
\hline 7. curriculum design & 3.54 & .64 & $.19^{* *}$ & $.25^{* *}$ & $.35^{* *}$ & $.33^{* *}$ & $.35^{* *}$ & $.46^{* *}$ & 1 & & \\
\hline 8. leaning assessment & 3.89 & .56 & $.40^{* *}$ & $.33^{* *}$ & $.50^{* *}$ & $.49^{* *}$ & $.52^{* *}$ & $.58^{* *}$ & $.64^{* *}$ & 1 & \\
\hline 9. class management & 3.60 & .59 & $.22^{* *}$ & $.24^{* *}$ & $.41^{* *}$ & $.41^{* *}$ & $.43^{* *}$ & $.50^{* *}$ & $.68^{* *}$ & $.66^{* *}$ & 1 \\
\hline
\end{tabular}

$$
\text { ** } p<.01 \text {. }
$$

\subsection{The prediction of perceived MCEP from teacher gender and MCE workshop}

Table 4 showed the results of regression analysis of the prediction of MCEP from teachers' gender, indicating that teacher-perceived MCEP could not be predicted from teacher gender. In contrast, table 5 showed analysis results, which indicated that teachers' attendance of MCE workshop could significantly predict teacher-perceived MCEP at levels of teaching strategy $(\beta=.18 ; p<.001)$, curriculum design $(\beta=.24 ; p<.001)$, learning assessment $(\beta=.20 ; p<.001)$,

classroom management $(\beta=.22 ; p<.001)$, and overall $(\beta=.25 ; p<.001)$.

Table 4. Multiple regression analyses of gender predicting MCEP $(\mathrm{N}=464)$

\begin{tabular}{|c|c|c|c|c|c|c|c|c|c|c|c|c|c|c|}
\hline \multirow{2}{*}{$\begin{array}{l}\text { Independent } \\
\text { variables }\end{array}$} & \multicolumn{2}{|c|}{ teaching strategy } & \multicolumn{3}{|c|}{ curriculum design } & \multicolumn{3}{|c|}{ learning assessment } & \multicolumn{3}{|c|}{ classroom management } & \multicolumn{3}{|c|}{ overall } \\
\hline & $B$ & S.E. $\beta$ & $B$ & S.E. & $\beta$ & $B$ & S.E. & $\beta$ & $B$ & S.E. & $\beta$ & $B$ & S.E. & $\beta$ \\
\hline Constant & 4.14 & .03 & 3.52 & .04 & & 3.89 & .03 & & 3.57 & .04 & & 3.78 & .03 & \\
\hline \multirow[t]{3}{*}{ Gender } & .09 & .05 & .08 & .06 & .06 & .02 & .05 & .01 & .08 & .06 & .07 & .07 & .05 & .07 \\
\hline & \multicolumn{2}{|c|}{$R=.08, R^{2}=.01$} & \multicolumn{3}{|c|}{$R=.06, R^{2}=.00$} & \multicolumn{3}{|c|}{$R=.01, R^{2}=.00$} & \multicolumn{3}{|c|}{$R=.07, R^{2}=.00$} & \multicolumn{3}{|c|}{$R=.07, R^{2}=.007$} \\
\hline & \multicolumn{2}{|c|}{$F(1,462)=3.15$} & \multicolumn{3}{|c|}{$F(1,462)=1.67$} & \multicolumn{3}{|c|}{$F(1,462)=0.08$} & \multicolumn{3}{|c|}{$F(1,462)=2.057$} & \multicolumn{3}{|c|}{$F(1,462)=2.07$} \\
\hline
\end{tabular}

Table 5. Multiple regression analyses of attendance of MCE workshop predicting MCEP $(\mathrm{N}=464)$

\begin{tabular}{|c|c|c|c|c|c|c|c|c|c|c|c|c|c|c|c|}
\hline \multirow{2}{*}{$\begin{array}{l}\text { Independent } \\
\text { variables }\end{array}$} & \multicolumn{3}{|c|}{ teaching strategy } & \multicolumn{3}{|c|}{ curriculum design } & \multicolumn{3}{|c|}{ learning assessment } & \multicolumn{3}{|c|}{ classroom management } & \multicolumn{3}{|c|}{ overall } \\
\hline & $\bar{B}$ & S.E. & $\beta$ & $\bar{B}$ & S.E & $\beta$ & $\bar{B}$ & S.E. & $\beta$ & $B$ & S.E & $\beta$ & $B$ & S.E. & $\beta$ \\
\hline Constant & 4.10 & .03 & & 3.42 & .04 & & 3.80 & .03 & & 3.50 & .04 & & 3.70 & .03 & \\
\hline \multirow{2}{*}{ Attendance } & \multicolumn{3}{|c|}{$R=.18, R^{2}=.03$} & \multicolumn{3}{|c|}{$R=.24, R^{2}=.06$} & \multicolumn{3}{|c|}{$R=.20, R^{2}=.04$} & \multicolumn{3}{|c|}{$R=.22, R^{2}=.05$} & \multicolumn{3}{|c|}{$R=.25, R^{2}=.06$} \\
\hline & \multicolumn{3}{|c|}{$F(1,462)=14.66$} & \multicolumn{3}{|c|}{$F(1,462)=27.54$} & \multicolumn{3}{|c|}{$F(1,462)=18.72$} & \multicolumn{3}{|c|}{$F(1,462)=23.87$} & \multicolumn{3}{|c|}{$F(1,462)=31.35$} \\
\hline
\end{tabular}




\subsection{The prediction of perceived MCEP from $M C E B$}

Table 6 showed the results of regression analyses of the prediction of perceived MCEP from each dimension of perceived MCEB. At teaching strategy level, the table showed analysis result, which indicated that teacher perceptions of MCEP were significantly associated with dimensions of gender and special need. The special need dimension $(\beta=.36 ; p<.001)$ was apparently the best predictor of perceived MCEP. Gender dimension was also significantly associated with $\operatorname{MCEP}(\beta=.13 ; p<.05)$. The MCEB dimensions explained $39 \%$ of the variance in perceived MCEP at this level $\left(R=.62 ; R^{2}=.39\right.$ and $\left.F(5,458)=57.67 ; p<.001\right)$.

At curriculum design level, the table showed analysis result, which indicated that teacher perceptions of MCEP were significantly associated with dimensions of pedagogy, gender, ethnicity and special need. Dimensions of ethnicity $(\beta=.23 ; p<.001)$ and special need $(\beta=.22$; $p<.001)$ were apparently the best predictors of perceived MCEP. Gender dimension $(\beta=.13 ; p$ $<.01)$ was also significantly associated with MCEP. However, pedagogy dimension $(\beta=-.15$; $p<.01)$ was negatively significantly associated with MCEP at this level. The MCEB dimensions explained $18 \%$ of the variance in perceived MCEP at this level $\left(R=.42 ; R^{2}=.18\right.$ and $F(5,458)=19.37 ; p<.001)$.

At learning assessment level, the table showed analysis result, which indicated that teacher perceptions of MCEP were significantly associated with dimensions of gender, ethnicity and special need. The special need dimension $(\beta=.27 ; p<.001)$ was apparently the best predictor of perceived MCEP. Dimensions of ethnicity $(\beta=.23 ; p<.001)$ and gender $(\beta=.09 ; p<.05)$ were also significantly associated with MCEP. The MCEB dimensions explained $33 \%$ of the variance in perceived MCEP at this level $\left(R=.58 ; R^{2}=.33\right.$ and $\left.F(5,458)=45.88 ; p<.001\right)$.

At classroom management level, the table showed analysis result, which indicated that teacher perceptions of MCEP were significantly associated with dimensions of gender, ethnicity and special need. The special need dimension $(\beta=.27 ; p<.001)$ was apparently the best predictor of perceived MCEP. Ethnicity dimension $(\beta=.23 ; p<.001)$ was also significantly associated with MCEP. However, pedagogy dimension $(\beta=-.17 ; p<.01)$ was negatively significantly associated with MCEP. The MCEB dimensions explained $24 \%$ of the 
variance in perceived MCEP at this level $\left(\mathrm{R}=.49 ; \mathrm{R}^{2}=.24\right.$ and $\left.\mathrm{F}(5,458)=29.45 ; p<.001\right)$.

At overall level, the table showed analysis result, which indicated that teacher perceptions of MCEP were significantly associated with dimensions of gender, ethnicity and special need.

The special need dimension $(\beta=.33 ; p<.001)$ was apparently the best predictor of perceived

MCEP. Dimensions of ethnicity $(\beta=.25 ; p<.001)$ and gender $(\beta=.11 ; p<.01)$ were also significantly associated with MCEP. The MCEB dimensions explained $38 \%$ of the variance in perceived MCEP at this level $\left(R=.62 ; R^{2}=.38\right.$ and $\left.F(5,458)=56.69 ; p<.001\right)$.

Table 6. Multiple regression analyses of dimensions of perceived MCEB predicting MCEP $(N=464)$

\begin{tabular}{|c|c|c|c|c|c|c|c|c|c|c|c|c|c|c|c|}
\hline \multirow{2}{*}{ MCEB } & \multicolumn{3}{|c|}{ teaching strategy } & \multicolumn{3}{|c|}{ curriculum design } & \multicolumn{3}{|c|}{ learning assessment } & \multicolumn{3}{|c|}{ classroom management } & \multicolumn{3}{|c|}{ overall } \\
\hline & $B$ & S.E. & $\beta$ & $B$ & S.E. & $\beta$ & $B$ & S.E. & $\bar{\beta}$ & $B$ & S.E. & $\beta$ & $B$ & S.E. & $\beta$ \\
\hline constant & .89 & .21 & & 1.41 & .29 & & .78 & .23 & & 1.23 & .25 & & 1.08 & .19 & \\
\hline pedagogy & .05 & .06 & .05 & -.21 & .08 & $-.15 * *$ & .02 & .06 & .02 & -.22 & .07 & $-.17 * *$ & -.09 & .05 & -.08 \\
\hline gender & .16 & .03 & $.13^{*}$ & .11 & .04 & $.13 * *$ & .07 & .03 & $.09 *$ & .06 & .04 & .07 & .07 & .03 & $.11 * *$ \\
\hline ethnicity & .13 & .05 & .05 & .27 & .07 & $.23 * * *$ & .23 & .06 & $.23 * * *$ & .25 & .06 & $.23 * * *$ & .22 & .05 & $.25 * * *$ \\
\hline Social class & .13 & .07 & .12 & .05 & .10 & .04 & .09 & .08 & .08 & .15 & .09 & .12 & .10 & .06 & .11 \\
\hline \multirow{4}{*}{$\begin{array}{l}\text { Special } \\
\text { need }\end{array}$} & .14 & .06 & $.36 * * *$ & .30 & .09 & $.22 * * *$ & .32 & .07 & $.27 * * *$ & .34 & .08 & $.27 * * *$ & .34 & .06 & $.33 * * *$ \\
\hline & \multicolumn{3}{|c|}{$R=.62, R^{2}=.39$} & \multicolumn{3}{|c|}{$R=.42, R^{2}=.18$} & \multicolumn{3}{|c|}{$R=.58, R^{2}=.33$} & \multicolumn{3}{|c|}{$R=.49, R^{2}=.24$} & \multicolumn{3}{|c|}{$R=.62, R^{2}=.38$} \\
\hline & \multicolumn{3}{|c|}{$F(5,458)=57.67$} & \multicolumn{3}{|c|}{$F(5,458)=19.37$} & \multicolumn{3}{|c|}{$F(5,458)=45.88$} & \multicolumn{3}{|c|}{$F(5,458)=29.45$} & \multicolumn{3}{|c|}{$F(5,458)=56.69$} \\
\hline & \multicolumn{3}{|c|}{$p=.000$} & \multicolumn{3}{|c|}{$p=.000$} & \multicolumn{3}{|c|}{$p=.000$} & \multicolumn{3}{|c|}{$p=.000$} & \multicolumn{3}{|c|}{$p=.000$} \\
\hline
\end{tabular}

\section{Discussion and conclusion}

This study examined the relationships among MCEBs, MCEP, gender, and workshop attendance. Data analysis yielded the following findings. First, female teachers scored higher than males on the pedagogy dimension on the MCEBS but no significant differences existed between male and female teachers on the MCEPS. This empirical data for Taiwan schools show that individual factors, teachers' gender affected their MCEBs.

Second, attending an MCE workshop significantly affected the teachers' MCEBs and MCEP. Teachers who had attended an MCE workshop scored higher on gender and social class dimensions than teachers who had never attended an MCE workshop, and they also had a higher score on all MCEBS dimensions, including teaching strategy, curriculum design, learning assessment, and classroom management than teachers who had never attended an MCE workshop. Moreover, attending an MCE workshop can significantly predict teacher-perceived MCEP. These findings were, to some extent, in line with those of several other studies, showing that courses or workshops in MCE positively impact in-service teachers' beliefs (Edwards \& Kuhlman, 2007; Wiggins, Follo, \& Eberly, 2007). Further, 
teachers' beliefs significantly influence how they plan, organize, and implement their lessons and their responsiveness to their students (Staub \& Stern, 2002; Stipek, Givvin, Salmon, \& MacGyvers, 2001; Fong \& Sheets, 2004; Leonard \& Leonard, 2006; McCall, 1995; Montano, Lopez-Torres, \& DeLissovoy, 2002). Thus, secondary school teachers must be encouraged to attend MCE workshops to cultivate their knowledge, skills and attitudes. With this knowledge and skill set they can successfully teach youth multicultural perspectives, including increased understanding, sensitivity, and appreciation of the history, values, experiences, and lifestyles of different groups.

The MCEBs and perceived MECP were positively corrected; dimensions of ethnicity and special needs were more strongly correlated than other dimensions. Regardless of teaching strategy, curriculum design, learning assessment, and classroom management levels, MCEBs significantly predicted perceived MCEP. The special needs dimension was the best predictor of perceived MCEP at any level. These findings have two crucial implications for teacher education. First, teacher education should offer future teachers MCE courses that equip them with sufficient knowledge of cultures, beliefs, attitudes, skills to provide students with the necessary multicultural awareness. Several scholars have advocate for teacher education and professional development in MCE to improve teacher education (Garm \& Karlsen, 2004; Sleeter \& Bernal, 2004; Merryfield, 1995; Holden \& Hicks, 2007). A number of scholars also have worked to improve pre-service teacher education for diverse K-12 students (Merryfield, 1996; Zeichner \& Hoeff, 1996). Other scholars have made efforts to increase cross-cultural experiences within diverse populations of pre-service teacher (Merryfield, 2002; Merryfield, 1995; Sahin, 2008). Second, the special needs of students should be a focus when preparing future teachers. Although this study only measured teachers' MCEBs and MCEP, it contributes to recent calls for additional evidence of the effects of teacher education programs on MCE and suggests that teacher educators create suitable systems that enhance MCE knowledge and abilities. Of course, future research can apply other measures (e.g., classroom observation of curriculum design and implementation related to MCE) to acquire evidence regarding improvements to MCE for teachers.

\section{Acknowledgments}

The authors would like to thank the National Science Council of the Republic of China, Taiwan for financially supporting this research under Contract No. NSC 101-2410-H-018-025-MY2.

\section{References}

Ambe, E. B. (2006). Fostering multicultural appreciation in pre-service teachers through multicultural curricular transformation. Teaching and Teacher Education, 22, 690-699. http://dx.doi.org/10.1016/j.tate.2006.03.005

Banks, J. A. (1997). Teaching strategies for ethnic studies (6 ${ }^{\text {th }}$ ed). Boston, MA: Allyn \& Bacon.

Banks, J. A. (2004). Multicultural education: Historical development, dimensions, and practices. In J. A. Banks \& C. A. McGee Banks (Eds.), Handbook of research on 
multicultural education ( $2^{\text {nd }}$ ed., pp. 3-29). San Francisco: Jossey-Bass. http://dx.doi.org/10.3102/0091732X019001003

Bennett, C. L. (2003). Comprehensive multicultural education: Theory and practice ( $5^{\text {th }}$ ed.). Boston, MA: Pearson Educational.

Davidman, L., \& Davidman, P. T. (2001). Teaching with a multicultural perspective: A practical guide $\left(3^{\text {rd }}\right.$ ed). Boston, MA: Addison-Wesley Educational Publishers Inc.

Edwards, S., \& Kuhlman, W. (2007). Culturally responsive teaching: do we walk our talk? Multicultural Education, 14(4), 45-49.

Fong, A., \& Sheets, R. H. (2004). Multicultural education: teacher conceptualization and approach to implementation. Multicultural Education, 12(1), 10-15.

Fullinwider, R. (2001). Multicultural education and cosmopolitan citizenship. International Journal of Educational Research, 35, 331-343. http://dx.doi.org/10.1016/S0883-0355(01)00028-3

Garm, N., \& Karlsen,G. E. (2004). Teacher education reform in Europe: the case of Norway; trends and tensions in a global perspective. Teaching and Teacher Education, 20, 731-744. http://dx.doi.org/10.1016/S0883-0355(01)00028-3

Hachfeld, A., Hahn, A., Schroeder, S., Anders, Y., Stanat, P., Kunter, M. (2011). Assessing teachers' multicultural and egalitarian beliefs: The Teacher Cultural Beliefs Scale. Teaching and Teacher Education, 27, 986-996. http://dx.doi.org/10.1016/j.tate.2011.04.006

Henson, K. T. (2004). Constructivist teaching strategies for diverse middle-level classrooms. Boston, MA: Pearson Education.

Holden, C., \& Hick, D. (2007). Making global connections: The knowledge, understanding and motivation of trainee teachers. Teaching and Teacher Education, 23, 13-23. http://dx.doi.org/10.1016/j.tate.2006.04.031

Hou, H. N. (2010). A study on teaching beliefs and practices of multicultural education of preschool teachers in central Taiwan. (Unpublished Master thesis). National Taichung University of Education, Taichung, Taiwan.

Leonard, P., \& Leonard, L. (2006). Teachers and tolerance: discriminating diversity dispositions. The Teacher Educator, 42(1), 30-62. http://dx.doi.org/10.1080/08878730609555392

Manning, M. L., \& Baruth, L. G. (2004). Multicultural education of children and adolescents $\left(4^{\text {th }}\right.$ ed). Boston, MA: Pearson Education.

McCall, A. (1995). Constructing conceptions of multicultural teaching: life experiences and teacher education. Journal of Teacher Education, 46(5), 340-350. http://dx.doi.org/10.1177/0022487195046005004

Merryfield, M. M. (1995). Institutionalizing cross-cultural experiences and international 
expertise in teacher education: The development and potential of a global education PDS network. Journal of Teacher Education, 46, 1-9. http://dx.doi.org/10.1177/0022487195046001005

Merryfield, M. M. (1996). Making connections between multicultural and global education: Teacher educators and teacher education programs. Washington DC: The American Association of Colleges for Teacher Education.

Merryfield, M. M. (2002). The difference a global educator can make. Educational Leadership, 60(2), 18-21.

Ministry of Education (2002). Teacher education law enforcement rules. Retrieved from the World Wide Web: http://www.edu.tw//EDU-WEB/EDU_MGT/MOECCS.

Montano, T., Lopez-Torres, L., \& DeLissovoy, N. (2002). Teachers as activists: teacher development and alternate sites of learning. Equity \& Excellence in Education, 35(3), 265-275. http://dx.doi.org/10.1080/713845315

National Council for Accreditation of Teacher Education. (2008). Professional standards for the accreditation of teacher preparation institutions. Retrieved from. http://www.ncate.org/LinkClick.aspx?fileticket $1 / 4$ nX43fwKc4Ak\%3d\&tabid $1 / 4474$.

Ndura, E., \& Dogbevia, M. K. (2013). Re-envisioning multicultural education in diverse academic contexts. Procedia - Social and Behavioral Sciences, 93, 1015 -1019. http://dx.doi.org/10.1016/j.sbspro.2013.09.321

Perkins, R. (2012). The multicultural awareness, knowledge, skills and attitudes of prospective teachers: A quantitative and heuristic phenomenological study (Doctoral dissertation). (Retrieved from www.unixl.com/dir/curriculum/missouri).

Peterson, M. W., \& Spencer, M. G. (1990). Understanding academic culture and climate. In W.G. Tierney (Ed.). Assessing academic climates and cultures (pp.1-21). San Francisco: Jossey-Bass.

Sahin, M. (2008). Cross-cultural experience in pre-service teacher education. Teaching and Teacher Education, 24, 1777-1790. http://dx.doi.org/10.1016/j.tate.2008.02.006

Sleeter, C., \& Bernal, D. D. (2004). Critical pedagogy, critical race theory, and antiracist education: implications for multicultural education. In J. A. Banks, \& C. M. Banks (Eds.), Handbook of research on multicultural education (2 ${ }^{\text {nd }}$ ed.). (pp. 240-258) San Francisco: Jossey-Bass.

Sogunro, O. A. (2001). Toward multiculturalism: Implications of multicultural education for schools. Multicultural $\quad$ Perspectives, $\quad 3(3), \quad$ 19-34. http://dx.doi.org/10.1207/S15327892MCP0303_5

Staub, F. C., \& Stern, E. (2002). The nature of teachers' pedagogical content beliefs matters for students' achievement gains: quasi-experimental evidence from elementary mathematics. Journal of Educational Psychology, 344-355. 
http://dx.doi.org/10.1037/0022-0663.94.2.344

Stevenson, Z., \& Gonzalez, L. (1992). Contemporary practices in multicultural approaches to education among largest American school districts. Journal of Negro Education, 61(3), 356-368. http://dx.doi.org/10.2307/2295253

Stipek, D. J., Givvin, K. B., Salmon, J. M., \& MacGyvers, V. L. (2001). Teachers' beliefs and practices related to mathematics instruction. Teaching and Teacher Education, 17, 213-226. http://dx.doi.org/10.1016/S0742-051X(00)00052-4

Suárez-Orozco, M. M. \& Sattin, C., (2007). Introduction in M. M. Suárez-Orozco (Ed.), Learning in the global era: International knowledge on globalization and education (pp.1-43). Berkeley and Los Angeles, CA: University of California Press.

Tang, H. Y. (2009). The study of civics and society teachers' multicultural literacy and teaching beliefs (Unpublished Master thesis). National Taiwan Normal University, Taipei, Taiwan.

UNESCO. (2004). Changing teaching practices: Using curriculum differentiation to respond to students' diversity. Paris: UNESCO.

Vedder, P., Horenczyk, G., Liebkind, K., \& Nickmans, G. (2006). Ethno-culturally diverse education settings: problems, challenges and solutions. Educational Research Review, 1, 157e168. http://dx.doi.org/10.1016/j.edurev.2006.08.007

Wen, W. J.(2008). The percipience and practice of multicultural education of kindergarten teachers in Hualien (Unpublished Master thesis). National Hualien Normal College. Hualien, Taiwan.

Wiggins, R. A., Follo, E. J., \& Eberly, M. B. (2007). The impact of a field immersion program on pre-service teachers' attitudes toward teaching in culturally diverse classrooms. Teaching and Teacher Education, 23(5), 653-663. http://dx.doi.org/10.1016/j.tate.2007.02.007

Williams, S. E., Nichols, Q. L., Williams, N. L. (2013). Public child welfare workers' perception of efficacy relative to multicultural awareness, knowledge and skills. Children and Youth Services Review, 35, 1789-1793. http://dx.doi.org/10.1016/j.childyouth.2013.08.002

Yang, S. K. (2002). Educational research for the dialectic process of globalization and localization. Paper presented at the Conference of European Education Research Association, Lisbon, Portugal.

Zeichner, K. M., \& Hoeff, K. (1996). Teacher socialization for cultural diversity. In J. Sikula (Ed.), Handbook of research on teacher eduction (pp. 525-547). New York: Macmillan Library. 